\title{
INCLUSÃO ESCOLAR DE UM ALUNO COM DEFICIÊNCIA INTELECTUAL: UM ESTUDO DE CASO DESENVOLVIDO EM PORTUGAL
}

\author{
SCHOOL INCLUSION OF A STUDENT WITH INTELLECTUAL \\ DISABILITY: A CASE STUDY DEVELOPED IN PORTUGAL
}

\section{INCLUSIÓN ESCOLAR DE UN ESTUDIANTE CON DISCAPACIDAD INTELECTUAL: UN ESTUDIO DE CASO DESARROLLADO EN PORTUGAL}

Jéssica Harume Dias Muto ${ }^{11}$

https://orcid.org/0000-0002-0977-6978

Lidia Maria Marson Postalli ${ }^{2}$

https://orcid.org/0000-0001-7560-697X

Manuela Sanches-Ferreira ${ }^{3}$

https://orcid.org/0000-0002-4693-3928

1 Universidade Federal de São Carlos, São Carlos, São Paulo - Brasil. E-mail: harume.muto@gmail.com

${ }^{2}$ Universidade Federal de São Carlos, São Carlos, São Paulo - Brasil. E-mail: lidiapostalli @ufscar.br

${ }^{3}$ Instituto Politécnico do Porto - Portugal. E-mail: manuelaferreira@ese.ipp.pt.

\section{Resumo}

O Programa de Ensino Individualizado (PEI) é um documento que descreve as medidas de aprendizagem por meio de orientações e desenvolvimento sistematizado de ensino para alunos que necessitam de suporte no processo de ensino e aprendizagem, no qual as metas devem atender às necessidades e singularidades do aluno, beneficiando o processo de inclusão. $\mathrm{O}$ presente trabalho teve como objetivo analisar o PEI de um aluno com deficiência intelectual matriculado em uma escola regular de Portugal, de modo a eleger um dos objetivos a ele propostos na área da leitura e escrita e elaborar uma intervenção que atendesse às suas

\footnotetext{
${ }^{1}$ Financiamento da Bolsa Estágio à Pesquisa no Exterior (BEPE) da Fundação de Amparo à Pesquisa do Estado de São Paulo (FAPESP) (Processo $n^{\circ}$ 2017/13749-0), vinculado ao projeto de Iniciação Científica FAPESP (Processo no 2015/23136-0).

${ }^{2}$ Financiamento pelo Edital Universal 01/2016 (CNPq, Processo n $\left.{ }^{\circ} 427409 / 2016-0\right)$ e é membro do Instituto Nacional de Ciência e Tecnologia sobre Comportamento, Cognição e Ensino (CNPq, Processo ${ }^{\circ}{ }^{4}$ 465686/20141; FAPESP, Processo n²014/50909-8; CAPES Processo n 88887.136407/2017-00).
} 
necessidades, avaliando seu desempenho continuamente. Neste trabalho, realizou-se o ensino de reconhecimento de 10 palavras iniciadas com a letra $\mathrm{P}$, ensinadas duas a duas, empregando-se os procedimentos de emparelhamento com o modelo (matching-to-sample $[M T S]$ ) e emparelhamento com o modelo com resposta construída (constructed response matching to sample [CRMTS]). Os resultados mostraram que o aluno apresentou avanços parciais no desempenho de habilidades alvo e não houve manutenção na avaliação após um mês. Os dados indicaram que o investimento no planejamento de ensino sistematizado e adequado torna-se de extrema relevância para o processo de ensino e aprendizado e o trabalho multidisciplinar.

Palavras-chave: Ensino Sistematizado. Programa de Ensino Individualizado. Educação Especial. Inclusão. Deficiência Intelectual.

\begin{abstract}
The Individual Education Program (IEP) is a document that disregards learning measures through a student's systematic guidance and development for some who need substrates other than teaching and learning processes, and not what goals should meet their needs and student singularities, may benefit or process of inclusion. This work aimed to analyze the student's IEP with an intellectual disability registered in regular school in Portugal, in order to choose one of the objectives proposed to this student in the area of reading and writing and to elaborate an intervention that meets the needs of this student, seeking to evaluate continuously the performance of the student. In this work, we applied the teaching of recognition of 10 words beginning with the letter $P$, taught two by two, using the matching-tosample (MTS) and the constructed response matching to sample model (CRMTS) procedures. The results showed that the student presented partial advances in the performance of target skills; and he did not present maintenance in the evaluation after one month. The data indicated that the investment in planning systematized and appropriate teaching becomes extremely relevant to the teaching and learning process and the importance of multidisciplinary.
\end{abstract}

Keywords: Systematized Teaching. Individualized Education Program. Special Education. Inclusion. Intellectual Disability.

\title{
Resumen
}

El Programa de Enseñanza Individualizada (PEI) es un documento que describe las medidas de aprendizaje a través de la orientación y el desarrollo sistematizado de la enseñanza para los estudiantes que necesitan de apoyo en el proceso de enseñanza y aprendizaje, en el que los objetivos deben satisfacer las necesidades y singularidades, beneficiándose el proceso de inclusión. El presente trabajo tuvo como objetivo analizar el PEI de un alumno con discapacidad intelectual matriculado en una escuela regular de Portugal, de manera a elegir uno de los objetivos que se le propusieron en el área de la lectura y escrita y realizar una intervención que satisficiera sus necesidades, evaluándose continuamente su desempeño. En este trabajo se realizó la enseñanza de reconocimiento de 10 palabras iniciadas con la letra $P$, enseñadas dos a dos, empleándose los procedimientos de emparejamiento con el modelo (matching-to-sample [MTS]) y emparejamiento con el modelo con respuesta construida (constructed response matching to sample [CRMTS]). Los resultados mostraron que el estudiante presentó avances parciales en el desempeño de las habilidades blanco y no hubo 
mantenimiento en la evaluación después de un mes. Los datos indicaron que la inversión en la planificación de la enseñanza sistematizada y adecuada se vuelve de extrema importancia para el proceso de enseñanza y aprendizaje y el trabajo multidisciplinario.

Palabras clave: Enseñanza Sistematizada. Programa de Enseñanza Individualizada. Educación Especial. Inclusión. Discapacidad Intelectual.

\section{Introdução}

Criar ambientes favorecedores para a aprendizagem é um objetivo desafiador para os profissionais que atuam como formadores, seja no ensino de uma habilidade acadêmica, de uma habilidade de vida diária, de uma habilidade profissional ou outras tantas possíveis situações de ensino-aprendizagem. Considerando o ambiente escolar, a inclusão pode ter sucesso se esses aprendizes tiverem suportes adequados e houver uma parceria contínua entre os profissionais e o professor da sala de aula regular, buscando contemplar os mesmos objetivos para o aluno com métodos e estratégias diferenciados daqueles de sala de aula (SANCHES; TEODORO, 2006; STAINBACK; STAINBACK, 1999; VILARONGA; MENDES, 2014). Uma das medidas que podem ser utilizadas para fundamentar essa parceria na promoção da inclusão é o Programa de Ensino Individualizado $\left(\mathrm{PEI}^{3}\right)$, no qual a elaboração sistematizada das estratégias de ensino deve atender às necessidades e singularidades do aluno, beneficiando seu processo de inclusão como público-alvo da educação especial.

O PEI pode ter algumas nuanças na definição e nos seus modelos de implementação, entretanto trata-se de um documento que pode contribuir para melhorar a qualidade do ensino, pois busca acompanhar o percurso escolar individual do aluno, considerando o repertório de habilidades, conhecimentos e desenvolvimento, idade cronológica e nível de escolarização já alcançado, reconhecendo e trabalhando com as demandas específicas do aluno (GLAT; VIANNA; REDIG, 2012; SMITH, 2008; STAINBACK; STAINBACK, 1999; TANNÚSVALADÃO; MENDES, 2018). Esse documento deve ser construído por um grupo que inclua professores e a equipe escolar, a família do aluno, se necessário, profissionais da saúde e, quando possível, o próprio aluno (KUPPER, 2000; SMITH, 2008). Sanches-Ferreira et al. (2013) consideram o PEI um documento fundamental no qual se descrevem todas as respostas educativas para os alunos com necessidades adicionais de suporte (NAS), estabelecendo todas as orientações para as situações de desenvolvimento e de aprendizagem. Também Thompson

\footnotetext{
${ }^{3}$ Em Portugal, o termo utilizado é "Programa Educativo Individual" (PORTUGAL, 2018).
} 
et al. (2009) descrevem o PEI como uma ponte entre "o que é" e o que "pode ser" a vida dos alunos.

Com a sistematização do ensino, o educador pode aplicar recursos ou medidas que possibilitem avaliar a eficácia e a eficiência do ensino proposto, permitindo identificar as falhas no procedimento e, principalmente, adequar as necessidades do aluno, buscando condições para a aprendizagem.

A elaboração de programas de ensino exige do profissional a formulação dos possíveis objetivos terminais a serem alcançados, ou seja, o que o aprendiz será capaz de realizar ao final do programa; além disso, devem ser definidos os objetivos intermediários, ou seja, objetivos específicos que atendam aos objetivos terminais (CORTEGOSO; COSER, 2011). Assim como a definição do objetivo de ensino, as autoras também destacam a importância da definição da resposta esperada e a descrição das condições propostas para a ocorrência do comportamento e as condições propostas após a ocorrência do comportamento. Essas condições permitem que o educador tenha um parâmetro de medida.

Os objetivos pautados no PEI se veem, contudo, muitas vezes, longe do desejado, descritos de maneira ampla e geral. Num estudo realizado por Sanches-Ferreira et al. (2013) usando, entre outros instrumentos, o Revised IFSP/IEP Goals and Objectives Rating Instrument (R-GORI), analisaram-se 2.697 objetivos inscritos em 135 PEIs de alunos com NAS. Os resultados mostraram que, em geral, os objetivos estão escritos de modo pouco claro, particularmente no que diz respeito à mensurabilidade. O estudo mostrou ainda que, quanto mais os alunos avançavam na escolaridade, mais a qualidade dos objetivos decrescia e que os alunos com currículo específico individual (uma das medidas dentro de um PEI) tinham poucos objetivos funcionais nos seus PEIs.

Mesmo que as políticas educacionais concebam que os alunos da educação especial tenham a garantia de diferenciações no processo educacional, no Brasil não há legislação que contemple a formulação do PEI para esses alunos, havendo apenas alguns estados e municípios que, em suas leis, indicam o direito a um plano educacional individualizado. Hoje, o respaldo em âmbito nacional consta na Resolução no 4 (BRASIL, 2009), que prevê um plano de atendimento educacional especializado, entretanto trata-se de um plano segregativo a um loco que não corresponde à filosofia da inclusão escolar, focando-se no serviço, e não nas necessidades do indivíduo (TANNÚS-VALADÃO; MENDES, 2018). Na realidade de 
Portugal, a qual o trabalho teve como foco de investigação, há indicação de um PEI na legislação, e nela contempla-se desde o processo de referenciação até a elaboração (PORTUGAL, 2008, 2018).

Diante do exposto, o presente trabalho teve como objetivo analisar o PEI de um aluno com deficiência intelectual matriculado em uma escola regular, de modo a eleger um dos objetivos a ele propostos na área da leitura e escrita e elaborar uma intervenção que atendesse às suas necessidades, buscando avaliar seu desempenho no ensino da habilidade alvo.

$\mathrm{Na}$ intervenção proposta, o objetivo de ensino foi o reconhecimento de palavras impressas (leitura e escrita), e, para atingi-lo, foram utilizadas como estratégias de ensino o emparelhamento com o modelo (matching to sample [MTS]) e emparelhamento com o modelo com resposta construída (constructed response matching to sample [CRMTS]), procedimentos que vêm sendo utilizados tanto em pesquisas científicas (DE ROSE, 2005; DE SOUZA; DE ROSE, 2006; MACKAY, 1985; SIDMAN; TAILBY, 1982) quanto no cotidiano da escola. Destaca-se que o presente trabalho se baseou no procedimento sistematizado, individualizado e informatizado de ensino de leitura e escrita (DE ROSE et al.,1989, 1992; DE SOUZA et al., 2004; DE SOUZA; DE ROSE, 2006) que se refere a um recurso de ensino suplementar e complementar para a aquisição de repertório inicial de leitura e escrita de palavras por alunos com dificuldades de aprendizagem em tais habilidades.

Pretende-se mostrar com o relato de experiência que um planejamento sistematizado de ensino de uma habilidade, contemplando um objetivo intermediário, etapas de ensino e avaliações contínuas, bem como uma avaliação geral de repertório conduzida antes e depois da intervenção, é fundamental para favorecer, facilitar e aumentar a eficácia desse processo de ensino e aprendizagem. Na maior parte das vezes, o aluno pode necessitar de adaptação na temporalidade, aumento de exposição diante da atividade/assunto e uso de recursos diferenciados para a efetiva aprendizagem. Assim, o registro do comportamento diante das condições de ensino oferecidas ao aprendiz torna-se essencial para a avaliação gradual e sistêmica do desempenho. 


\section{Caracterização do participante}

Bernardo ${ }^{4}$ foi referenciado para o atendimento dos serviços de Educação Especial aos 5 anos e 11 meses de idade, no primeiro ano da pré-escola ${ }^{5}$, quando apresentava algumas dificuldades e atraso no desenvolvimento de habilidades em relação à idade, segundo o professor. Com base nessa sinalização, a equipe multidisciplinar de avaliação desencadeou os processos conducentes a uma avaliação que teve por referência a Classificação Internacional de Funcionalidade, Incapacidade e Saúde (CIF) (ORGANIZAÇÃO MUNDIAL DA SAÚDE, 2004). Dessa avaliação resultou um perfil de funcionalidade que é composto por características específicas apresentadas pelo aluno em três categorias: funções do corpo, atividade e participação e fatores ambientais. Para cada categoria houve descrições do desempenho da criança, constando as suas dificuldades e as suas potencialidades; nesse caso, especificamente na categoria "fatores ambientais", foram apontadas questões sobre a guarda judicial da criança, que foi passada de sua progenitora para a avó paterna.

Com base nesse perfil de funcionalidade, a equipe indicou que o aluno deveria ser objeto de um PEI, pois considerou-se que o seu sucesso dependeria de um constante acompanhamento individualizado e especializado. Além disso, no PEI de Bernardo eram garantidos apoio pedagógico personalizado e adequações curriculares individuais e no processo de avaliação.

\section{Desenvolvimento metodológico}

O presente trabalho, resultado de um estágio-pesquisa com o auxílio da Fundação de Amparo à Pesquisa do Estado de São Paulo (FAPESP), foi conduzido em Portugal com um aluno de 10 anos e 7 meses, do sexo masculino, com diagnóstico de atraso no desenvolvimento intelectual, matriculado no $3^{\circ}$ ano do I Ciclo do Ensino Básico ( $1^{\circ}$ ao $4^{\circ}$ ano) no ano letivo de 2017/2018 em uma escola localizada na periferia do distrito do Porto, em Portugal, considerada de desenvolvimento socioeconômico baixo.

O estágio-pesquisa foi realizado na escola, em uma sala de recursos de Educação Especial que o aluno frequentava. Para a implementação do procedimento de ensino foram

\footnotetext{
${ }^{4}$ Nome fictício.

${ }^{5}$ No Brasil, refere-se à Educação Infantil. 
utilizadas palavras, letras e figuras em papel-cartão, e, para registro de desempenhos, utilizaram-se protocolos em papéis, lápis e caneta.

Para a elaboração do procedimento de ensino aplicado foram realizadas a análise do PEI do aluno e reuniões com a professora da Educação Especial, que efetuava os atendimentos semanalmente. As seguintes metas curriculares foram consideradas: conhecer o alfabeto e os fonemas; ler palavras em voz alta; desenvolver o conhecimento da ortografia; transcrever textos; redigir corretamente; e desenvolver precisão motora (escrever letras de imprensa maiúsculas). Em relação à sugestão da professora, a mesma relatou que o aluno apresentava alguns pré-requisitos referentes a leitura e escrita e a indicação de que não havia sido trabalhada a associação entre fonemas e símbolos (letras/sílabas/palavras).

Diante disso elaborou-se um ensino de reconhecimento de 10 palavras iniciadas com a letra $\mathrm{P}^{6}$, ensinadas duas a duas, empregando-se os procedimentos de emparelhamento com o modelo e emparelhamento com o modelo com resposta construída para cópia e ditado, baseado no paradigma de equivalência de estímulos (DE ROSE; 2005; DE SOUZA; DE ROSE, 2006; MACKAY, 1985; SIDMAN, 1994; SIDMAN; TAILBY, 1982). A Figura 1 ilustra relações ensinadas e avaliadas.

\footnotetext{
${ }^{6}$ A escolha por aplicar um conjunto de palavras iniciadas com a letra $\mathrm{P}$ foi sugestão da professora da sala regular que indicou que trabalharia com o ensino dessas palavras durante o ano letivo.
} 
Figura 1 - Relações ensinadas e avaliadas.

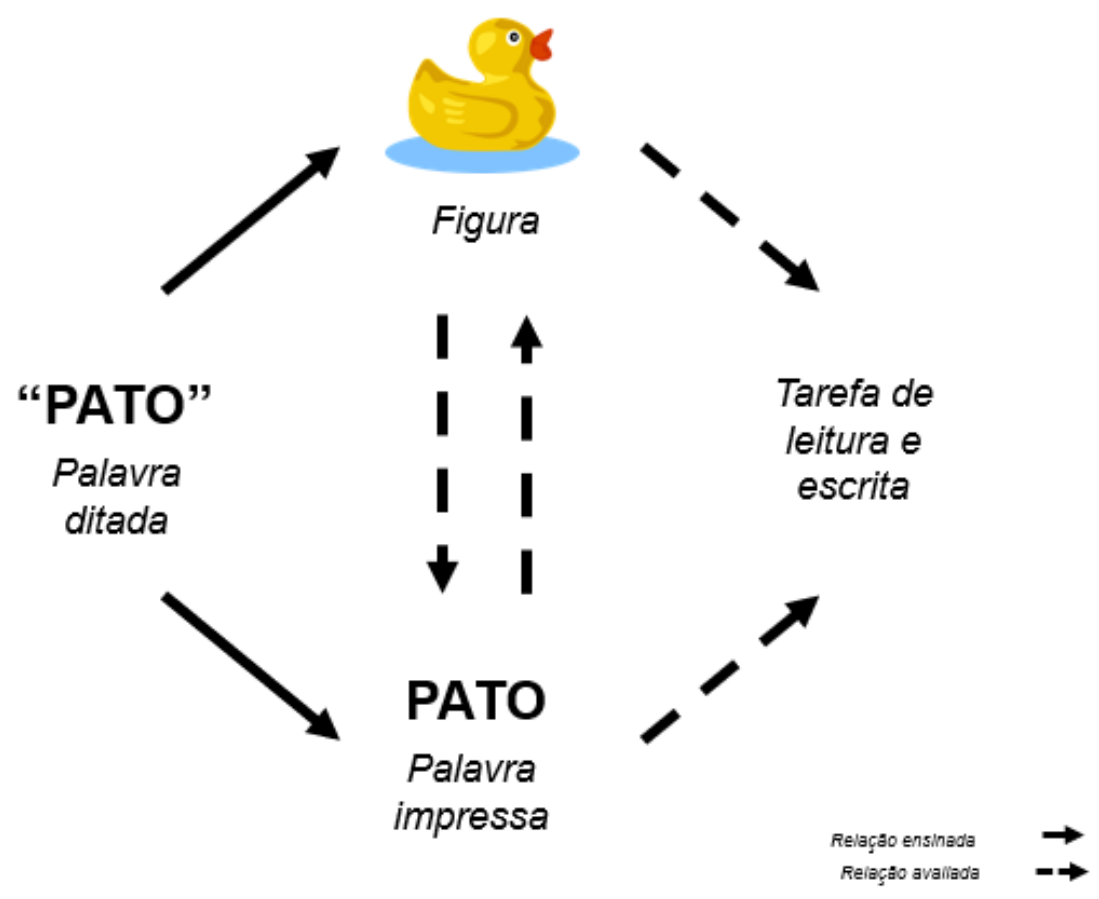

Fonte: Elaboração própria.

As 10 palavras foram organizadas em cinco passos de ensino, conforme indicado na Tabela 1. Cada passo iniciava com o bloco de ensino de emparelhamento entre palavra ditada e figura correspondente, sendo seis tentativas no total, três de cada palavra, com o critério de $100 \%$ de acertos para passar para o próximo bloco ou, caso contrário, repetir o bloco por, no máximo, três vezes. Ao atingir o critério, o próximo bloco foi composto por 12 tentativas da relação entre palavra ditada e palavra impressa, seis de escrita por composição de letras, sendo três diante da palavra ditada e três diante da palavra impressa (cópia), totalizando 18 tentativas. 
Tabela 1 - Configuração da tarefa de um passo de ensino.

\begin{tabular}{|c|c|c|c|c|}
\hline & TT & Modelo & Resposta 1 & Resposta 2 \\
\hline Relação & & Palavra ditada & \multicolumn{2}{|c|}{ Figuras } \\
\hline \multirow[t]{2}{*}{ Parte A } & 1 & Palavra A & Palavra B & Palavra A \\
\hline & 2 & Palavra B & Palavra B & Palavra A \\
\hline \multirow{4}{*}{$\begin{array}{c}\text { Critério: } \\
100 \% \text { de acerto } \\
\text { Se errar, repetir o } \\
\text { bloco }\end{array}$} & 3 & Palavra B & Palavra A & Palavra B \\
\hline & 4 & Palavra A & Palavra A & Palavra B \\
\hline & 5 & Palavra B & Palavra B & Palavra A \\
\hline & 6 & Palavra A & Palavra B & Palavra A \\
\hline \multirow{2}{*}{ Relação } & & \multirow{2}{*}{ Modelo } & \multicolumn{2}{|c|}{ Palavras/letras impressas } \\
\hline & & & Resposta 1 & Resposta 2 \\
\hline \multirow{6}{*}{ Parte B } & 1 & Palavra B (pal. dit) & Palavra B & Palavra A \\
\hline & 2 & Palavra B (pal. dit) & Palavra A & Palavra B \\
\hline & 3 & Palavra A (pal. dit) & Palavra A & Palavra B \\
\hline & 4 & Palavra B (pal. dit) & Palavra B & Palavra A \\
\hline & 5 & Palavra A (pal. dit) & Palavra B & Palavra A \\
\hline & 6 & Palavra A (pal. dit) & Palavra A & Palavra B \\
\hline \multirow{12}{*}{$\begin{array}{l}\text { Critério: } \\
\text { \% de acerto nas } \\
\text { tarefas de } \\
\text { parelhamento e } \\
\text { cópia }\end{array}$} & 7 & Palavra B (pal. dit) & Palavra A & Palavra B \\
\hline & 8 & Palavra A (pal. dit) & Palavra B & Palavra A \\
\hline & 9 & Palavra B (pal. impres.) & \multicolumn{2}{|c|}{ Letras para construir a resposta } \\
\hline & 10 & Palavra B (pal. dit) & Palavra B & Palavra A \\
\hline & 11 & Palavra A (pal. dit) & Palavra B & Palavra A \\
\hline & 12 & Palavra A (pal. impres.) & \multicolumn{2}{|c|}{ Letras para construir a resposta } \\
\hline & 13 & Palavra B (pal. dit) & Palavra A & Palavra B \\
\hline & 14 & Palavra B (pal. impres.) & \multicolumn{2}{|c|}{ Letras para construir a resposta } \\
\hline & 15 & Palavra B (pal. dit) & \multicolumn{2}{|c|}{ Letras para construir a resposta } \\
\hline & 16 & Palavra A (pal. dit) & Palavra A & Palavra B \\
\hline & 17 & Palavra A (pal. impres.) & \multicolumn{2}{|c|}{ Letras para construir a resposta } \\
\hline & 18 & Palavra A (pal. dit) & \multicolumn{2}{|c|}{ Letras para construir a resposta } \\
\hline
\end{tabular}

Os retângulos pintados em cinza correspondem à resposta correta, respeitando a ordem da disposição das palavras na mesa.

Fonte: Elaboração própria. 
Diante das respostas corretas, a pesquisadora consequenciava o aluno mostrando que ele havia acertado, por exemplo, com um elogio do tipo "isso mesmo" e, diante de resposta incorreta, a ela dizia "não, não é" e reapresentava a mesma tentativa. O critério foi de $100 \%$ de acertos nas tarefas de emparelhamento e cópia. Se atingisse o critério, o aluno realizaria o próximo passo de ensino (com duas novas palavras); caso não o atingisse, realizaria o mesmo passo novamente por, no máximo, três vezes. Se não alcançasse o critério após três repetições do passo, o aluno passaria para o próximo passo de ensino. A Figura 2 mostra exemplos de uma tentativa da relação entre palavra ditada e figura (painel da esquerda) e de escrita por composição - cópia (painel da direita). As tarefas foram realizadas com as palavras confeccionadas pela pesquisadora e posicionadas sobre uma mesa. Durante as tarefas, a pesquisadora disponibilizava a ordem e a sequência de cada uma.

Figura 2 - Exemplos de uma tentativa da relação entre palavra ditada e figura e de escrita por composição - cópia

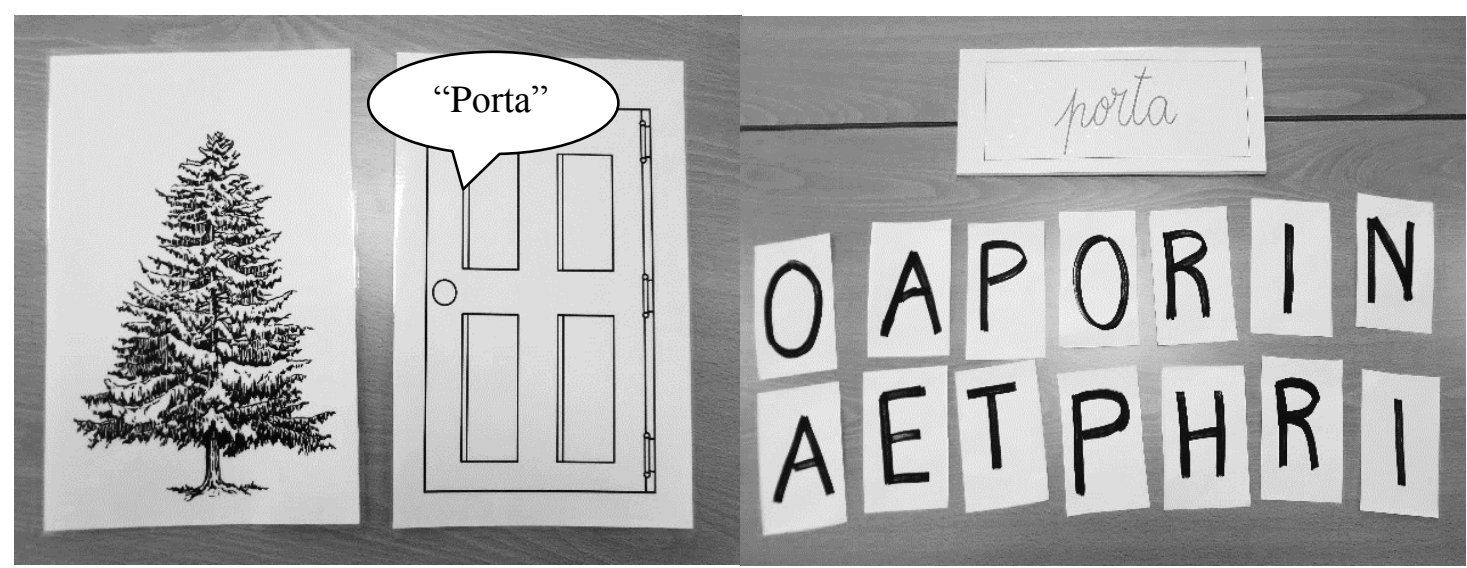

Fonte: Elaboração própria.

O procedimento de ensino foi programado com a aplicação de pré-teste, pós-teste e follow-up conduzido um mês após o pós-teste para medir os conhecimentos prévios e posteriores ao ensino. A Tabela 2 apresenta as relações avaliadas e o número de tentativas. 
Tabela 2 - Relações avaliadas e número de tentativas no pré-teste, pós-teste e follow-up.

\begin{tabular}{c|c}
\hline Relações avaliadas & $\mathrm{N}^{\circ}$ de tentativas \\
\hline Tarefas de seleção & 10 \\
Emparelhamento entre palavra ditada e figura & 10 \\
Emparelhamento entre palavra ditada e palavra impressa & 10 \\
Emparelhamento entre figura e palavra impressa & 10 \\
Emparelhamento entre palavra impressa e figura & \\
Tarefas de produção & 10 \\
Nomeação de figuras & 10 \\
Nomeação de palavras impressas & 23 \\
Nomeação de letras impressas - consoantes e vogais do alfabeto & 5 \\
Nomeação de vogais (isoladas e em ordem) & 10 \\
Ditado com letra cursiva & 10 \\
Cópia com letra cursiva & \\
\hline
\end{tabular}

Fonte: Elaboração própria.

\section{Resultados}

\subsection{Intervenção: reconhecimento de palavras}

\subsubsection{Sessões de ensino}

A Figura 3 apresenta a porcentagem de acertos nas relações ensinadas em cada passo de ensino realizado por Bernardo. 
Figura 3 - Porcentagens de acertos nas relações ensinadas em cada passo de ensino.

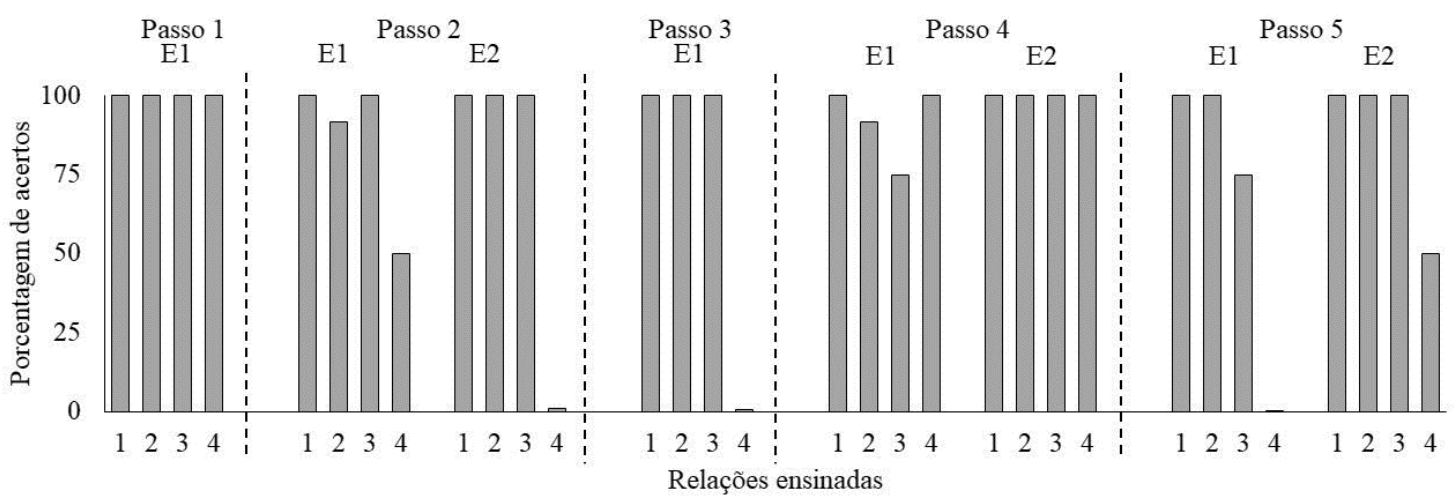

Passo 1 - pato e poço; Passo 2 - pinha e pinto; Passo 3 - Paulo e Pilar; Passo 4 - pai e pão; Passo 5 - porta e pinheiro. 1 - Palavra ditada-figura; 2 - palavra ditada-palavra impressa; 3 - cópia por composição; 4 - ditado por composição.

Fonte: Elaboração própria com base nos dados obtidos no procedimento.

De modo geral, Bernardo realizou poucas sessões de ensino. Nos passos 1 (pato e poço) e 3 (Paulo e Pilar), o aluno atingiu o critério em uma sessão. No passo 3, ele escreveu "Parlo" em vez de Paulo e "Paulo" em vez de Pilar, apresentando desempenho nulo na tarefa de ditado.

Para os três demais passos, Bernardo realizou duas sessões. No passo 2 (pinha e pinto), na primeira sessão, ele apresentou $100 \%$ de acertos na relação entre palavra ditada e figura e na cópia; na relação entre palavra ditada e palavra impressa, acertou 11 em 12 tentativas $(91,6 \%)$ e 50\% de acertos em ditado ("pina" diante de "pinto"). Na segunda sessão, o aluno demonstrou $100 \%$ de acertos nas habilidades ensinadas, exceto no ditado. No ditado, Bernardo compôs "pia” em vez de pinha e "pita" em vez de pinto. No passo 4 (pai e pão), ele apresentou $100 \%$ de acertos na relação entre palavra ditada e figura e ditado, 91,6\% na relação entre palavra ditada e palavra impressa e $75 \%$ na cópia. Na segunda sessão, o aluno apresentou $100 \%$ de acertos em todas as relações. No último passo de ensino (porta e pinheiro), Bernardo, na primeira sessão, apresentou $100 \%$ de acertos nas relações de emparelhamento, $75 \%$ na cópia e 50\% no ditado ("pinhieto" diante de pinheiro, e "pieto" diante de porta). Na segunda sessão, ele apresentou $100 \%$ de acertos nas relações de emparelhamento e em cópia por composição. Em ditado por composição, Bernardo escreveu "pieo" em vez de pinheiro, atingindo $50 \%$ de acertos. 


\subsubsection{Pré-teste, Pós-teste e teste de manutenção de desempenho (follow-up)}

A Figura 4 apresenta a porcentagem de acertos em cada relação avaliada no pré-teste, pós-teste e follow-up. No pré-teste, o aluno apresentou $100 \%$ de acertos na relação entre palavra ditada e figura e $60 \%, 50 \%$ e $30 \%$ de acertos, respectivamente, nas relações entre palavra ditada e palavra impressa, figura e palavra impressa e palavra impressa e figura. Bernardo apresentou $100 \%, 70 \%$ e $61,5 \%$ de acertos, respectivamente, na nomeação de vogais, de figuras e de letras impressas e desempenho nulo na nomeação de palavras. Nas tarefas de escrita, cópia manuscrita e ditado manuscrito, o aluno apresentou $70 \%$ e $10 \%$ de acertos, respectivamente.

Nas tarefas de pós-teste, Bernardo manteve $100 \%$ de acertos na relação entre palavra ditada e figura e apresentou aumento no desempenho das relações entre palavra ditada e palavra impressa (70\% de acertos) e entre palavra impressa e figura (60\% de acertos). Nas tarefas de nomeação, Bernardo manteve o desempenho na nomeação de vogais e apresentou 100\% de acertos na nomeação de figuras, $84,6 \%$ na nomeação de letras impressas e $70 \%$ na nomeação de palavras. Em escrita, Bernardo apresentou $90 \%$ de acertos na cópia manuscrita e desempenho nulo no ditado manuscrito.

Figura 4 - Porcentagem de acertos nas relações avaliada no pré-teste, pós-teste e follow-up.

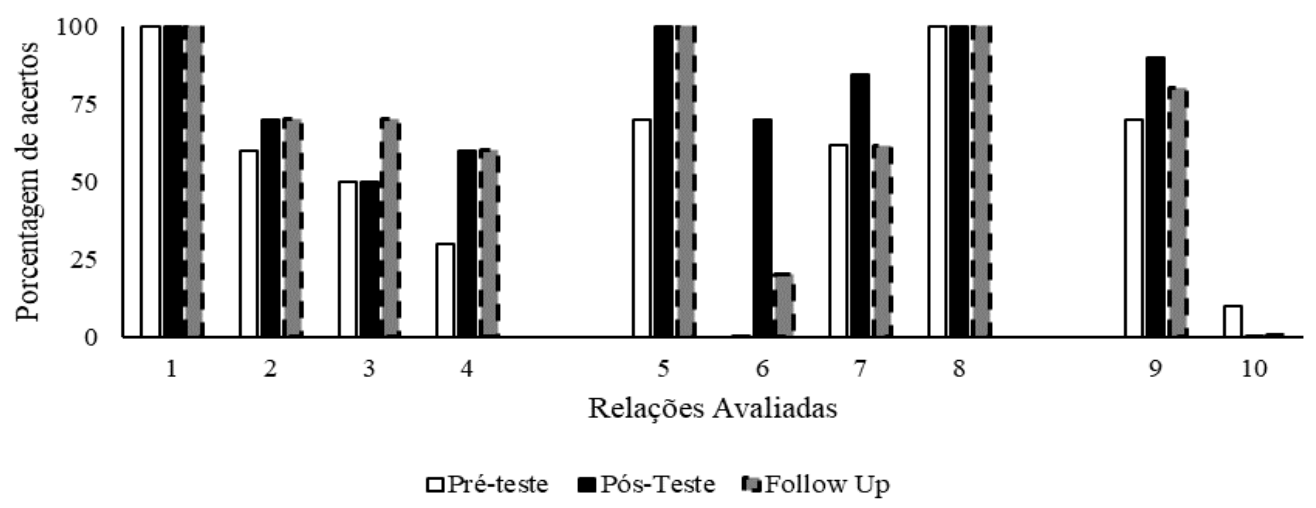

1 - Palavra ditada-figura; 2 - palavra ditada-palavra impressa; 3 - figura-palavra impressa; 4 - palavra impressafigura; 5 - nomeação de figuras; 6 - nomeação de palavras; 7 - nomeação de letras impressas; 8 - nomeação de vogais; 9 - cópia manuscrita; 10 - ditado manuscrito.

Fonte: Elaboração própria com base nos dados obtidos do procedimento de coleta de dados. 
Após um mês da aplicação do pós-teste, foi avaliada a manutenção do desempenho do aluno (follow-up). Bernardo manteve o mesmo desempenho apresentado no pós-teste nas relações entre palavra ditada e figura, palavra ditada e palavra impressa, palavra impressa e figura, indicando aumento no desempenho da relação entre figura e palavra impressa. Ele manteve o desempenho de $100 \%$ de acertos na nomeação de figuras e vogais e apresentou queda na nomeação de palavras e letras impressas. Bernardo também obteve desempenho mais baixo na cópia manuscrita e manteve nulo o desempenho em ditado por composição.

$\mathrm{Na}$ tarefa de nomeação de palavra, o aluno, no primeiro momento, diante das 10 palavras, emitiu respostas que não correspondiam à palavra. Bernardo utilizou sílabas aleatórias para nomear a palavra e, diante de três delas, ele utilizou três palavras para nomear, sendo "essa" para "pinto, "rena" para "Pilar" e "perna" para "pato". No pós-teste, o aluno apresentou um desempenho $70 \%$ maior que no pré-teste, errando somente três palavras, nomeando "pinha" para "poço", "pinheiro" para "pinha" e "pinha" para "pato". Na avaliação de manutenção, o aluno mostrou queda no desempenho em relação ao pós-teste, acertando a leitura de duas palavras, "pai" e "pinheiro". As demais, ele utilizou as palavras ensinadas para leitura, entretanto não estando sob controle de todos os elementos (letras) das palavras. $\mathrm{Na}$ tarefa escrita manuscrita diante da palavra ditada, o aluno apresentou um acerto durante o préteste, em que escreveu corretamente a primeira palavra (pai). No pós-teste e no follow-up, Bernardo manteve desempenho nulo, mas observou-se que a escrita das palavras iniciava com a letra "P". Em seis palavras, Bernardo apresentou a primeira sílaba corretamente. Em dois momentos, escreveu "pipa" como resposta aos estímulos "pão" e "pinheiro", demonstrando não estar no controle de todos os elementos que compõem a palavra. No pós-teste, ele escreveu a primeira sílaba em $80 \%$ das palavras e manteve os $80 \%$ de acertos no follow-up, porém com um erro em palavras diferentes e uma igual, a palavra Pilar, escreveu "pae" no pós-teste e "pai" no follow-up.

\section{Discussão}

O presente trabalho, diante de seu objetivo, verificou que a legislação portuguesa, na época (hoje atualizada pelo Decreto-Lei $\mathrm{n}^{\circ}$ 54/2018, PORTUGAL, 2018), utilizava os processos de referenciação para o atendimento de alunos com necessidades educacionais especiais, realizando a elegibilidade de alunos para essa modalidade de ensino por meio da 
CIF, que respaldava e unificava o processo avaliativo do aluno em relação à funcionalidade do indivíduo dentro de diversos contextos, e da implementação e do funcionamento de um documento único que acompanhava o aluno por toda sua vida escolar (PEI). Destaca-se que a CIF, inscrita na abordagem biopsicossocial, permite uma avaliação sistêmica e multidimensional da qual resulta um perfil de funcionalidade. $\mathrm{O}$ uso de instrumentos padronizados permite a definição de objetivos de ensino e o estabelecimento e acompanhamento das estratégias empregadas e desempenhos obtidos.

$\mathrm{Na}$ pesquisa realizada por Sanches-Ferreira, Silveira-Maia e Alves (2014), profissionais indicaram a importância do uso da CIF como instrumento para crianças e jovens para a melhor compreensão da funcionalidade dos alunos e descrição da influência ambiental. Também foi constatado, em uma revisão sistemática da literatura, que há uma forte presença de estudos de países de língua inglesa, principalmente da Europa e da América do Norte, destacando o uso da CIF e CIF-CJ (MORETTI; ALVES; MAXWELL, 2012), evidenciando, portanto, a necessidade de avanços na discussão da utilização de instrumentos padronizados e da elaboração e implementação de PEI em outros países.

No Brasil, a identificação e o processo de elaboração de um encaminhamento ou atendimento para a educação especial requer medidas que sustentem os argumentos indicando por que são necessárias ações complementares, suplementares ou até substitutivas ao processo de ensino tradicional, uma vez que o público-alvo da educação especial tem direito a um financiamento além da sala de aula regular. Ademais, conforme a legislação brasileira, o diagnóstico é critério para receber esse financiamento e o atendimento especializado (BRASIL, 2011). Esses argumentos são relevantes para compreender e determinar se tais ações serão significativas para o processo educacional do aluno.

Em relação aos instrumentos, no Brasil, há cartilhas do Ministério da Educação que indicam e exemplificam algumas práticas para os alunos público-alvo da Educação Especial, mas são apenas documentos norteadores. Os processos de avaliação, relatórios de atendimento, planejamentos, entre outros aspectos relacionados com a inclusão escolar, estão interligados com a formação dos profissionais, podendo a prática não estar associada ao que consta em lei, apresentando divergências na interpretação e execução da lei (OLIVEIRA; MANZINI, 2016), o que dificulta uma continuidade e/ou padronização dos atendimentos especializados da educação especial realizados no Brasil. 
A realidade portuguesa contava com uma legislação vigente (PORTUGAL, 2008) no período do estágio (realizado em 2017) que denotava medidas para esse processo de avaliação e de atendimento, respaldando todo o território português, auxiliando os professores na construção de um documento único e contínuo e favorecendo também os próprios alunos no processo educacional diante de mudança de professor ou escola. Especificamente ao desmembramento de um planejamento maior (PEI), quanto a objetivos de ensino menores (anual, semestral, trimestral ou diário), ressalta-se que a sistematização e a organização sequencial e gradual tornam-se essenciais para facilitar e favorecer a aprendizagem do aluno (DE SOUZA et al., 2004; KUBO; BOTOMÉ, 2001; MARINOTTI, 2004; MATOS, 2001; STROMER; MACKAY; STODDARD, 1992). A sistematização de procedimento de ensino permite que o educador aplique recursos ou medidas que avaliem a eficácia e a eficiência do ensino proposto, possibilitando identificar as falhas no procedimento e, principalmente, adequar as necessidades do aluno, buscando condições para sua aprendizagem e evitando o seu fracasso (SKINNER, 1972).

Ressalta-se que este trabalho teve por objetivo principal mostrar que um ensino planejado e constantemente avaliado pode favorecer e facilitar o processo de ensino e aprendizagem. Com isso, a proposta foi exemplificar e buscar reflexões acerca do caminho a ser percorrido ao se planejar um procedimento de ensino diante de um desenvolvimento educacional para um aluno público-alvo da educação especial. A sistematização de um planejamento com objetivos principais deve contemplar objetivos específicos que garantam o processo em pequenas etapas para que seja conquistado aquilo que foi previsto e planejado pelo professor e sua equipe escolar, terapeutas, família e, principalmente, pelo aluno. Ainda, buscou-se mostrar que trabalhar no ensino de pequenas habilidades dentro de um objetivo maior estabelecido em um plano individualizado torna-se mais significativo, uma vez que podem ser consideradas as especificidades de cada aluno, buscando adaptações no processo de ensino para a aprendizagem, seja no tempo, currículo, materiais, entre outras estratégias. Neste estudo, de maneira breve, foi apresentado um exemplo de como implementar um procedimento de ensino contemplando um objetivo específico de um plano maior, no caso, o PEI.

No presente trabalho, mesmo com o pouco tempo para a realização das tarefas e, consequentemente, a ausência de oportunidade de aprimorar o procedimento para atender às necessidades do aluno, observou-se, de modo geral, que Bernardo apresentou pequenas 
melhoras no desempenho em poucas sessões de ensino realizadas. Considera-se que o procedimento de ensino apresentou efeitos no reconhecimento de palavras, sugerindo que, se aplicado por mais sessões e com mais palavras iniciadas por diferentes letras, poderia auxiliar o aluno a reconhecer palavras e, logo, dar início ao processo de leitura e escrita, além de contribuir para a manutenção dos desempenhos. Sugere-se que trabalhos futuros avaliem as condições de ensino empregadas em tempo adequado, replanejando quando necessário e buscando realizar uma educação inclusiva com o sucesso da aprendizagem do aluno.

Adotar o PEI como um documento norteador para as práticas inclusivas auxilia no processo da construção de um ensino pautado nas reais necessidades de aprendizagem do aluno, para além do desenvolvimento acadêmico, mas também social, principalmente daqueles com deficiência intelectual (GLAT; REDIG, 2017; GLAT; VIANNA; REDIG, 2012; PLETSCH; GLAT, 2012). Assim, mostra-se necessária uma reestruturação na cultura das práticas pedagógicas para atender às reais necessidades de aprendizagem para que, de fato, ocorra uma inclusão dos alunos público-alvo da educação especial na rede regular de ensino brasileira. Considera-se imprescindível uma mudança para que ocorra a prática em trabalho multidisciplinar, buscando maximizar a contribuição de cada membro da equipe para potencializar o desenvolvimento do aluno. Além disso, cabe ressaltar a importância e a relevância das práticas baseadas em evidências na educação especial (COOK; TANKERSLEY; LANDRUM, 2009; ODOM et al., 2005). Hoje, pela experiência obtida com o trabalho realizado em um outro país, analisa-se que a legislação brasileira necessita ser revista para atender a alunos com necessidades educacionais em sala de aula e fora dela, principalmente no que se refere à avaliação para elegibilidade para o atendimento.

Por fim, para planejar um ensino, o professor deve se perguntar: (a) quem deve ser ensinado, (b) o que deve ser ensinado, (c) com que finalidade isso deve ser ensinado, (d) quanto deve ser ensinado (qual o nível de competência que se espera que o estudante possua) e (e) como deve ser ensinado (CORTEGOSO; COSER, 2011; LUNA, 2000; SANCHESFERREIRA, 2007). Isso auxiliará o educador a nortear suas práticas para favorecer o processo de aprendizagem de um aluno com qualquer especificidade no desenvolvimento. 


\section{Referências}

BRASIL. Resolução n⿳ 4, de 2 de outubro de 2009. Institui Diretrizes Operacionais para o Atendimento Educacional Especializado na Educação Básica, modalidade Educação Especial. Ministério da Educação, Brasília, DF, 2009.

BRASIL. Decreto $n^{0}$ 7.611, de 17 de novembro de 2011. Dispõe sobre a educação especial, o atendimento educacional especializado e dá outras providências. Brasília, DF, 2011.

COOK, B. G.; TANKERSLEY, M.; LANDRUM, T. J. Determining Evidence-Based Practices in Special Education. Exceptional Children, v. 75, n. 3, p. 365-383, 2009.

CORTEGOSO, A. L.; COSER, D. S. Elaboração de programas de ensino: material autoinstrutivo. Série Apontamentos. São Carlos, SP: Edufscar, 2011.

DE ROSE, J. C. Análise comportamental da aprendizagem de leitura e escrita. Revista Brasileira de Análise do Comportamento, v. 1, p. 29-50, 2005.

DE ROSE, J. C. et al. Aquisição de leitura após história de fracasso escolar: Equivalência de estímulos e generalização. Psicologia: Teoria e Pesquisa, v. 5, p. 325-346, 1989.

DE ROSE, J. C. et al. Stimulus equivalence and generalization in reading after matching to sample by exclusion. In: HAYES, S. C.; HAYES, L. J. (Orgs.), Understanding verbal relations, Reno, Nevada: Context Press, 1992. p. 69-82.

DE ROSE, J. C; DE SOUZA, D.; HANNA, E. S. Teaching reading and spelling: Exclusion and stimulus equivalence. Journal of Applied Behavior Analysis, v. 29, p. 451-469, 1996.

DE SOUZA, D. G. et al. Análise comportamental da aprendizagem de leitura e escrita e a construção de um currículo suplementar. In: HÜBNER M. M. C.; MARINOTTI, M. (org.). Análise do comportamento para a educação: contribuições recentes. Santo André, SP: ESETec, 2004. p. 177-203.

DE SOUZA, D. G.; DE ROSE, J. C. Desenvolvendo programas individualizados para o ensino de leitura. Acta Comportamentalia, v. 14, p. 77-98, 2006.

GLAT, R.; REDIG, A. G. Programa educacional especializado para capacitação e inclusão no trabalho de pessoas com deficiência intelectual. Avaliação e Políticas Públicas em Educação, v. 25, p. 1-26-26, 2017.

GLAT, R.; VIANNA, M. M.; REDIG, A. G. Plano Educacional Individualizado: uma estratégia a ser construída no processo de formação docente. Ciências Humanas e Sociedade em Revista, v. 34, n. 12, p. 79-100, 2012.

KUBO, O.; BOTOMÉ, S. P. Ensino-aprendizagem: uma interação entre dois processos comportamentais. Interação, v. 5, p. 133-171, 2001.

KUPPER, L. A guide to the individualized education program. 2000. Disponível em http://www.ed.gov/parents/needs/speced/iepguide/iepguide.pdf. Acesso em: 19 set. 2019. 
LUNA, S. V. Contribuições de Skinner para a educação. In: PLACCO, V. M. N. de S. (org.). Psicologia \& Educação: revendo contribuições. São Paulo: Educ, 2000. p. 145-179.

MACKAY, H. A. Stimulus equivalence in rudimentary reading and spelling. Analysis and Intervention in Developmental Disabilities, v. 6, p. 373-387, 1985.

MARINOTTI, M. Processos comportamentais envolvidos na aprendizagem de leitura e escrita. In: HÜBNER, M. M. C.; MARINOTTI, M. (org.). Análise do comportamento para a educação: contribuições recentes. Santo André, SP: ESETec, 2004. p. 201-220.

MATOS, M. A. Análise de contingências no aprender e no ensinar. In: ALENCAR, E.S. (org.). Novas contribuições da Psicologia aos processos de ensino e aprendizagem. São Paulo: Cortez, 2001. p. 143-165.

MORETTI, M.; ALVES, I.; MAXWELL, G. A systematic literature review of the situation of the international classification of functioning, disability, and health and the international classification of functioning, disability, and health-children and youth version in education: A useful tool or a flight of fancy? American Journal of Physical Medicine \& Rehabilitation, v. 91, n. 13 Suppl. 1, p. S103-S117, 2012.

ODOM et al. Research in Special Education: Scientific Methods and Evidence-Based Practices. Exceptional Children, v. 71, n. 2, p. 137-148, 2005.

ORGANIZAÇÃO MUNDIAL DA SAÚDE (OMS). Classificação Internacional de Funcionalidade, Incapacidade e Saúde. Tradução e revisão: Amélia Leitão, 2004, 238p.

PLETSCH, M. D.; GLAT, R. A escolarização de alunos com deficiência intelectual: uma análise da aplicação do Plano de Desenvolvimento Educacional Individualizado. Linhas Críticas, v. 18, n. 35, p. 193-208, 2012.

PORTUGAL. Decreto-Lei no 3 de 7 de janeiro de 2008, Ministério da Educação, Lisboa, Portugal, p. 154-164, 2008.

PORTUGAL. Decreto-Lei no 54 de 6 de julho de 2018, Ministério da Educação, Lisboa, Portugal, p. 2918-2928, 2018.

SANCHES, I.; TEODORO, A. Da integração à inclusão escolar: cruzando perspectivas e conceitos. Revista Lusófona de Educação, v. 8, p. 64-83, 2006.

SANCHES-FERREIRA, M. Educação Regular, Educação Especial: uma história de separação. Porto, Edições Afrontamento, 2007.

SANCHES-FERREIRA, M. et al. How individualised are the Individualised Education Programmes (IEPs): an analysis of the contents and quality of the IEPs goals. European Journal of Special Needs Education, v. 28, p. 507-520, 2013.

SANCHES-FERREIRA, M.; SILVEIRA-MAIA, M.; ALVES, S. The Use of the International Classification of Functioning, Disability and Health, Version for Children and Youth (ICF$\mathrm{CY}$ ), in Portuguese Special Education Assessment and Eligibility Procedures: The 
Professionals' Perceptions. European Journal of Special Education Needs, v. 29, p. 327343, 2014.

SIDMAN, M. Equivalence Relations and Behavior: a research story. Boston, MA: Authors Cooperative Publishers, 1994.

SIDMAN, M.; TAILBY, W. Conditional discrimination $v s$. matching to sample: An expansion of the testing paradigm. Journal of the Experimental Analysis of Behavior, $v$. 37, p. 5-22, 1982.

SKINNER, B. F. Tecnologia de ensino. São Paulo: Edusp, 1972.

SMITH, D. D. Programa Individualizado de Educação Especial. In: SMITH, D. D.

Introdução à Educação Especial: ensinar em tempos de inclusão, Porto Alegre: Artmed, 2008, p. 52-75.

STAINBACK, S.; STAINBACK, W. Inclusão: um guia para educadores. Porto Alegre: Artmed, 1999.

STROMER, R.; MACKAY, H. A.; STODDARD, L. T. Classroom Application of stimulus equivalence technology. Journal of Behavioral Education, v. 2, p. 225-256, 1992.

OLIVEIRA, C. C. B.; MANZINI, E. J. Encaminho e perfil do Público-Alvo da Educação Especial de uma Sala de Recursos Multifuncionais: estudo de caso. Revista Brasileira de Educação Especial, v. 22, p. 559-576, 2016.

THOMPSON, J. V. et al., Conceptualizing Supports and the Support Needs of People with Intellectual Disability. Intellectual and Development Disabilities, v. 47, p. 135-146, 2009.

TANNÚS-VALADÃO, G.; MENDES, E. G. Inclusão escolar e o planejamento educacional individualizado: estudo comparativo sobre práticas de planejamento em diferentes países.

Revista Brasileira de Educação, v. 23, p. 1-18, 2018.

VILARONGA, C. A. R.; MENDES, E. G. Ensino Colaborativo para o apoio à inclusão escolar: práticas colaborativas entre os professores. Revista Brasileira de Estudos

Pedagógicos, v. 95, p. 139-151, 2014.

Enviado em: 07/04/2020

Aprovado em: 23/02/2021

Publicado em: 15/06/2021 